\title{
Polish Geological Survey On the Never-Ending Geology quest - contribution to the OneGeology initiative as an example of challenges emerging from technological changes
}

\author{
Katarzyna Jóźwik $^{\text {a, *, Urszula Stępień }}{ }^{\text {a }}$, Marcin Słodkowski ${ }^{\text {a }}$ \\ ${ }^{a}$ Polish Geological Institute - National Research Institute, katarzyna.jozwik@pgi.gov.pl, urszula.stepien@pgi.gov.pl, \\ marcin.slodkowski@pgi.gov.pl \\ * Corresponding author
}

Keywords: Thematic maps, Geological maps, GeoSciML, GeoJSON

\begin{abstract}
:
We all witness some of ongoing geological processes or their results in our lives, starting from spectacular phenomena such as volcanic explosions and earthquakes up to animal shells accumulating at the bottom of the sea. Current processes reflect the past ones to a large extent and so today's solid limestone rock had once been a heap of seashells. Geology never ends, nor does the work with digital geological data.

In a modern day world, we join efforts with other geological surveys and organizations to develop common models and vocabularies to properly describe our data, in other words - to describe our limestone in a way that makes it clear for everybody that this is actually a limestone nor a dolostone or a chalk. However, standards used for data description and exchange need to be developed systematically in line with the technological changes, thus (simplifying) it is not enough to describe the limestone once.
\end{abstract}

The Polish Geological Institute - National Research Institute (PGI-NRI) acts as the Polish Geological Survey and recognizes the need of implementing and staying up-to-date with international standards. That is why the PGI-NRI has participated in the global OneGeology initiative from its very beginning. OneGeology, the international initiative of the geological surveys of the world, was officially launched in Brighton (UK) in 2007. Three years later, as a result of the OneGeology project, a first GeoSciML implementation was presented. The applied technology has been further developed on a global scale in the OneGeology initiative as well as beyond, and GeoSciML (Geoscience Markup Language, a GML specification for geological data description and exchange) became an official OGC standard in 2017.

In the frame of OneGeology, the PGI-NRI provides WMS/WFS services with Polish geological maps to the scale of 1:1 000 000, in particular: a surficial geological map, a pre-Cenozoic basement map and a basement horizontal cutting map (with 6 levels of horizontal cutting). The maps were originally compiled by the PGI-NRI in the years 2008-2013 in accordance with the contemporary OneGeology guidelines. However due to the changes that have been introduced to the GeoSciML schemas and vocabularies over the years and because of the overall technological development, both the PGI-NRI data and technical solutions needed to be upgraded to the present standards and current OneGeology recommendations.

Therefore, in the frame of the latest PGI-NRI project (2019-2021), the above mentioned maps were updated to meet the requirements of the newest GeoSciML schema. Data structure and terms (together with the relevant links/URIs) used for describing geological units (stratigraphy, lithology and genesis of deposits) were reviewed and adjusted to the OneGeology and other international recommendations e.g. CGI, OGC, INSPIRE. The OneGeology initiative favors the GeoSciML encoding so far but introducing GeoJSON (the Internet Engineering Task Force specification no. RFC 7946) is also considered.

Apart from the changes in the data structure and description, technological upgrade included server and software changes - previously used MapServer with dedicated connecting software (1 GE Connector) has been replaced with GeoServer with an app-schema plugin mapping file. After tests and a review of available technologies this solution was chosen as an optimal one for data publication in terms of maintaining the interoperability of geological data and meeting economy and performance criteria. The maps have been made available through new web services on the OneGeology Global geoportal as well as on the geoportal of the European Geological Data Infrastructure (EGDI).

The PGI-NRI next step, planned for the years 2021-2022 will be to review scientific geological data presented on the maps. It is important to remember that geological knowledge constantly develops and thanks to the emergence of new technologies, this development is now more rapid than ever. The interoperability projects developed on the basis of open licenses and specifications (eg. RFC 7946) create useful and simplified technological solutions instead of complex standards. The OneGeology initiative would be a good testing ground for the implementation of a new geological data exchange standard based on the GeoJSON format. It is also worth to note that the latest concept 
OneGeology considers as one of its future directions is a concept of developing a geological digital twin, the idea that has dominated the international geological society recently. 